\title{
AVALIAÇÃo DO USO DE FILME DE ANIMAÇÃO INFATIL NA PERSPECTIVA DO ENSINO DE MAMÍFEROS
}

\author{
José Djalma de Souza ${ }^{1}$; Priscila Gomes Coutinho²; Paulo Diêgo Elias do Nascimento ${ }^{3}$; Juliana \\ Rosa Farias da Silva ${ }^{4}$; Argus Vasconcelos de Almeida ${ }^{5}$ \\ ${ }^{1}$ Licenciatura em Ciências Biológicas. Universidade Federal Rural de Pernambuco. Email: jdds.djalma@hotmail.com \\ ${ }^{2}$ Licenciatura em Ciências Biológicas. Universidade Federal Rural de Pernambuco. \\ ${ }^{3}$ Licenciatura em Ciências Biológicas. Universidade Federal Rural de Pernambuco. \\ ${ }^{4}$ Licenciatura em Ciências Biológicas. Universidade Federal Rural de Pernambuco. \\ ${ }^{5}$ Professor Doutor. Universidade Federal Rural de Pernambuco. Email: argus.almeida@gmail.com
}

\section{Introdução}

A superlotação em salas de aula, baixos salários dos profissionais, a falta de manutenção adequada da estrutura física dos prédios escolares, sem falar na defasagem metodológica e didática, faz com que sejam buscadas novas técnicas que possam ser aplicadas nesse contexto (LIMA e VASCONCEOS, 2006). Por isso, o educar não se limita a repassar informações ou mostrar apenas um caminho, aquele que o professor considera como sendo o mais correto, mas é ajudar a pessoa a tomar consciência de si mesma, dos outros e da sociedade, oferecendo várias ferramentas para que o aluno possa escolher entre os vários caminhos possíveis, aquele que for compatível com seus valores, sua visão de mundo e com as circunstâncias adversas que ainda encontrará em seu futuro (ROJAS, 2002).

Sendo assim, os filmes vêm sendo utilizados como material didático principalmente no Ensino de Ciências desde o início da difusão do cinema como diversão. Imagens que registravam a reprodução animal, ciclo de vida das plantas, eclipses solares, entre outras, tornavam as explicações mais compreensíveis e antes da primeira guerra mundial, a França já usava o cinema como recurso didático (OLIVEIRA, 2006).

Ao usar o cinema como instrumento de auxilio pedagógico, pode-se questionar e debater com os alunos a respeito da percepção que estes apresentam sobre a complexidade da construção de fatos científicos, concepção e história da ciência (SANTOS; SHEID, 2012). Os filmes são meras ferramentas, recursos didáticos. É a forma como podemos usá-los que dará o enriquecimento ao nosso trabalho. E isto não se fará por formas mecânicas ou exposições de teorias, mas pela reflexão crítica que cada participante venha aprender a desenvolver, ampliando assim suas competências, suas habilidades, sua capacidade de discernimento (CASTILHO, 2004). Nunes (2006) também faz notar que os filmes de animação deveriam apresentar os desafios da profissão de cientista, reaproximando a ciência da vida, o que contribuiria com a divulgação científica. Esse tipo de tratamento [do 
cientista] reforça preconceitos e trabalha fortemente na construção do imaginário, pois, um público com pouco acesso a outras fontes de informação, tenderá a dar importância, mesmo que eles não tenham consciência disso (SIQUEIRA, 2006).

\section{Fundamentação Teórica}

Nesse sentido, surge a ideia do antropomorfismo, onde o espectador compreende o personagem animado, independente da sua forma visual (animal, humana ou robótica), dotado de uma personalidade exclusivamente humana. Ou seja, o personagem do desenho animado pode ser visto como uma metáfora de um determinado comportamento humano. Lakoff e Johnson (2002) classificam como personificação, as metáforas ontológicas, quando objetos físicos são idealizados como seres humanos. O artista americano Winsor McCay foi o primeiro animador a trabalhar personalidades em seu personagem "como recurso expressivo e de identificação com o público" (LUCENA, 2001).

O antropomorfismo significou, portanto, um importante passo para a evolução da linguagem da animação à medida em que possibilitou a expressão do artista, que então passa a ser capaz de narrar, criticar, divertir e emocionar através dos seus personagens (GINO, 2003).

A metáfora é um recurso puramente humano, presente "em todas as partes, porque é uma fonte perene da criatividade humana". É a concepção de um novo sentido “com base na fusão de dois conceitos ou ideias" (MOURA, 2012).

\section{Metodologia}

\section{Levantamento bibliográfico}

As fontes básicas utilizadas na introdução foram na discussão de artigos científicos acerca do uso do cinema no ensino, as possibilidades de abordagens desses materiais e as limitações dessas atividades.

\section{Escolha do filme}

A princípio foi feita uma pesquisa exploratória através de um levantamento de filmes de animação que possuíam como personagens principais animais, preferencialmente mamíferos. Existe uma quantidade consideravelmente grade de títulos, que são potencialmente utilizados como recurso didático em aulas de Ciências, por professores de ensino fundamental.

Para a escolha final, verificou-se aspectos do filme que poderia haver associações com temas e/ou conteúdos dos Mamíferos, e que os mesmos pudessem ser utilizados como recurso didático. 
“Zootopia (2016): Zootopia é uma cidade diferente de tudo o que você já viu. Formada por "bairros-habitat", como a elegante Praça Sahara e a gelada Tundralândia, essa metrópole abriga uma grande diversidade de animais irreverentes sempre prontos para encarar uma nova e divertida aventura. Quando Judy Hopps (voz de Monica Iozzi) chega em Zootopia, ela descobre que ser a primeira coelha da equipe da polícia, formada por animais grandes e fortes, não é nada fácil. Determinada a provar seu valor, ela embarca em uma aventura atrapalhada e bemhumorada, ao lado do malandro raposo Nick Wilde (voz de Rodrigo Lombardi) para desvendar um grande mistério. Além de Monica Iozzi e Rodrigo Lombardi emprestarem suas vozes para os protagonistas do filme, Judy Hopps e Nick Wilde, na versão brasileira do filme, o jornalista Ricardo Boechat dá voz ao personagem Boi Chá, o famoso jornalista da bancada do Zoo News. Para deixar tudo ainda mais divertido e com muito brilho, a cantora Shakira dará voz à personagem Gazelle, a maior estrela pop de Zootopia, além de interpretar a canção "Try Everything", da trilha sonora do filme. Dos mesmos criadores de Frozen e Operação Big Hero, Zootopia estreia 17 de março nos cinemas. "Fonte: Disney Entertainment.

\section{Classificação dos personagens}

Para a análise e avaliação da abordagem da Classe Mammalia no filme, foi usado como principal critério, os animais que possuem papel principal. Foram catalogados em uma tabela para fins de classificação zoológica e futura analise em entrevistas. Em um total de quinze personagens/animais analisados.

\section{Ficha de avaliação}

Elaborou-se uma proposta metodológica para o filme, tendo como objeto de estudo os temas, contextos e situações apresentadas no filme, de modo a relacionar e pensar em abordagens com a visão zoológica dos personagens/animais. 1. Adequabilidade do filme ao público alvo; 2. Potencial de uso em atividades didático-pedagógicas (potencial e área de aplicação); 3. Comportamento esperado para cada personagem/animal.

\section{Entrevistas}

As entrevistas foram feitas com crianças, público ao qual o filme destina-se. Foi feito o levantamento da idade e série do entrevistado. As perguntas versavam sobre " $O$ que são os mamíferos?", "Conhece algum mamífero?" e "(Caso tenha assistido ao filme). Reconhece algum mamífero?".

Após as perguntas abertas, para os entrevistados que já assistiram ao filme, foi feito um levantamento através do reconhecimento dos personagens/animais através das figuras. Por possuir apenas personagens/animais mamíferos as respostas deveriam ser "SIM" ou "NÃ $O$ " para os 
animais pertencerem a classe Mammalia. Foram entrevistados um total de dez alunos de uma escola de ensino fundamental da cidade do Recife-PE com média de idade de onze anos.

As perguntas tiveram como objetivo de auxiliar no encontro dos resultados.

\section{Resultados e Discussões}

Resultado das entrevistas. (Ver Tabela 3).

Tabela 3: Resultados das entrevistas.

\begin{tabular}{|c|c|c|c|}
\hline & $\begin{array}{l}\text { O que são os } \\
\text { mamíferos? }\end{array}$ & $\begin{array}{l}\text { Conhece algum } \\
\text { mamífero? }\end{array}$ & $\begin{array}{l}\text { (Caso tenha assistido ao filme). } \\
\text { Reconhece algum mamífero? }\end{array}$ \\
\hline Aluno A & $\begin{array}{l}\text { São aqueles que } \\
\text { mamam quando } \\
\text { pequenos. }\end{array}$ & $\begin{array}{l}\text { Sim...meus irmãos } \\
\text { e meus dois } \\
\text { cachorros, mel e } \\
\text { Marvin. }\end{array}$ & Coelho, onça, puma, raposa, leão. \\
\hline Aluno B & $\begin{array}{l}\text { Animais que se } \\
\text { alimentam do leite } \\
\text { materno para } \\
\text { sobreviver. }\end{array}$ & Gato. & Sim. Coelho e o leão. \\
\hline Aluno C & $\begin{array}{l}\text { São seres vivos que } \\
\text { nascem da barriga } \\
\text { da mãe...tem o } \\
\text { corpo coberto de } \\
\text { pelos e mamam. }\end{array}$ & $\begin{array}{l}\text { Sim, baleia, leão, } \\
\text { vaca. }\end{array}$ & $\begin{array}{l}\text { Sim. onça, rato, preguiça, urso. leão, } \\
\text { puma, raposa e coelho. }\end{array}$ \\
\hline
\end{tabular}

Para os todos os critérios utilizados foram encontrados resultados significativos. No primeiro ponto "Adequabilidade do filme ao público alvo", quanto ao alcance, além do público-alvo ao qual o filme se destina, mostra-se irrestrita, podendo ser facilmente assistido por pessoas de qualquer idade. Sendo assim, não possui contra recomendação no que diz respeito a momentos de entretenimento. Sua Linguagem é de fácil entendimento e a narrativa é leve, é predominantemente feita de diálogos entre os personagens, em nenhum momento o interlocutor é participante do diálogo, ficando apenas na condição de ouvinte.

No que diz respeito aos conteúdos visuais e verbais de cenas específicas, por todo o filme consegue-se reconhecer comportamento dos personagens de acordo com o hábito natural do animal, apesar da antropomorfização forte e predominante, que sempre esteve presenta na história humana (Vizachri, 2014), indo ao encontro de outro critério de comportamento esperado para cada personagem/animal, que em geral foi alta similaridade, mas pouca verossimilidade.

Detectou-se que potencial de uso em atividades didático-pedagógicas (potencial e área de aplicação) para o filme analisado é baixo se levar em consideração a livre 
interpretação de cada telespectador. Pode ser criteriosamente usada, desde que, haja a orientação previamente para identificação de cada animal diferindo do personagem.

\section{Conclusões}

Podemos considerar que para um melhor entendimento do uso de animações infantis para o processo de ensino/aprendizagem, faz-se necessário, que seja feita uma análise criteriosa por parte de quem promove tal atividade. Apesar do filme ter sido lançado recentemente, ainda neste ano de 2016, traz muitas semelhanças no tipo de abordagem animal com outros títulos anteriores e até mais antigos. Por isso, podemos julgar como um instrumento ainda fraco para o ensino de zoologia, pela necessidade do gênero filme, de haver o surrealismo ou realismo fantástico dos filmes infantis. E além disso, serviu para uma análise crítica reconhecendo os pontos positivos e negativos do uso produto verificado.

\section{Referências}

CASTILHO, A; BEZERRA, C; MARQUES, E.C; BARROS, L; VÉRAS, N. G. Filmes para ver e aprender. Rio de Janeiro. Qualitymark, 2004.

GINO, Maurício S. A Expressão e Recepção do Pensamento Analógico/Metafórico por Meio da Animação Cinematográfica. 2003. 152 f. Dissertação (Mestrado em Educação e Tecnológica) Centro Federal de Educação Tecnológica de Minas Gerais - CEFET-MG, Belo Horizonte, 2003.

LAKOFF, George e JOHNSON, Mark. Metáforas da Vida Cotidiana. Trad. Maria Sophia Zanotto e Vera Maluf. Campinas: Mercado de Letras, 2002.

LIMA KEC; VASCONCELOS SD. Análise da metodologia de ensino de ciências nas escolas da rede municipal de Recife. Ensaio: aval. pol. públ. Educ., Rio de Janeiro, v.14, n.52, p. 397-412, jul./set. 2006.

LUCENA, Alberto. J. Arte da animação. Técnica e estética através da história. São Paulo: Editora Senac São Paulo, 2001.

MOURA, Heronides. Vamos Pensar em Metáforas?. São Leopoldo: Editora Unisinos, 2012.

NUNES, C. Ciência e TV: a união possível e desejável. Revista Ciência e Cultura, Campinas, v.58, n.4, p.10-11, 2006.

OLIVEIRA JB. Cinema e imaginário científico. Hist. Cienc, saude-Mang. 2006 outubro; 13(suplemento): p. 133-50.

ROJAS, J. O lúdico na construção interdisciplinar da aprendizagem: uma pedagogia do afeto e da criatividade na escola. Rio de Janeiro: ANPED, 2002. Disponível em: <http://www.anped.org.br/25/excedentes25/jucimararojast07.rtf> . Acesso em: 10/06/2016. 
SANTOS, E. G; SHEID, N. M. J. Dicas de Filmes para aprender sobre Historia da Ciência. Santo Angelo-RS, 2012.

SIQUEIRA, D. C. O. Superpoderosos, submissos: os cientistas na animação televisiva. In: MASSARANI, L. (Org.). O pequeno cientista amador: a divulgação científica e o público infantil. Rio de Janeiro: Vieira \& Lent: UFRJ, Casa da Ciência: FIOCRUZ, 2005. p.23-32 